\title{
EMPREENDEDORISMO NO SETOR PÚBLICO: A INFLUÊNCIA DAS CARACTERÍSTICAS ORGANIZACIONAIS
}

DOI: 1014211/regepe.v5i1.320

Artigo recebido em: 27/10/2015 Artigo aprovado em: 03/03/2016

Denise Aparecida Hipólito Borges - Universidade Federal de Lavras ${ }^{1}$ Marcelo Márcio Romaniello - Universidade Federal de Lavras ${ }^{2}$ Mozar José de Brito - Universidade Federal de Lavras $^{3}$

\begin{abstract}
Resumo: O empreendedorismo durante muito tempo esteve atrelado ao setor privado como uma característica inerente e exclusiva das organizações desta esfera. No entanto, a Administração Pública nos últimos anos também tem apostado na introdução do empreendedorismo no seu setor. Definido em termos de tomada de decisão, inovação e proatividade, a literatura aponta o empreendedorismo público como uma ação capaz de melhorar a alocação dos recursos, mas que precisa de um ambiente organizacional favorável ao seu desenvolvimento. Diante disso, o objetivo deste estudo foi analisar a relação entre as características organizacionaisestruturais, administrativas, culturais e ambientais, com o empreendedorismo público compreendendo como elas podem influenciar essas ações. Para tanto, foi conduzida uma pesquisa em uma Prefeitura Municipal localizada na região sudeste de Minas Gerais. Tal pesquisa se destaca como exploratória, de natureza mista na qual foi utilizada a triangulação de instrumentos para a coleta de dados. Os resultados mostram que as características estudadas de fato influenciam o empreendedorismo público existindo relação positiva para a presença dos fatores hierarquia, formalidade, flexibilidade, autonomia, recompensas, especialização, accountability, multiplicidade de objetivos, orientação para os resultados, responsabilidade legal e para a competição e relação negativa para a presença dos fatores participação e influência política.
\end{abstract}

Palavras-chave: Gestão Pública Municipal; Organizações Públicas; Orientação Empreendedora; Brasil.

\section{ENTREPRENEURSHIP IN THE PUBLIC SECTOR: THE INFLUENCE OF ORGANIZATIONAL FEATURES}

Abstract: Entrepreneurship for a long had time been linked to the private sector as an inherent and unique feature of the organizations in this sphere. However, the

\footnotetext{
${ }^{1}$ Endereço:. Rua Paulo Menicucci, no40, Bairro Jardim América, Lavras/MG- CEP: 37200-000 Email: denisehipolito@yahoo.com.br

${ }^{2}$ E-mail: mromaniello@dae.ufla.br

${ }^{3}$ E-mail: mozarjdb@dae.ufla.br
}

BORGES, D. A. H.; ROMANIELLO, M. M.; BRITO, M. J. Empreendedorismo no setor público: a influência das características organizacionais. Revista de Empreendedorismo e Gestão de Pequenas Empresas, v.5, n.1, 2016. 
public administration in recent years has also invested in the introduction of entrepreneurship in its industry. Defined in terms of decision-making, innovation and proactivity, the literature indicates the public entrepreneurship as a capable action to improve the allocation of resources, but it needs a favorable organizational environment for their development. Thus, the aim of this study is to analyze the relationship between the characteristics organizacionais-structural, administrative, cultural and ambientais, with the public entrepreneurship understanding how they can influence these actions. Therefore, a search was conducted in a City Hall located in the southeastern region of Minas Gerais. Such research stands out as exploratory, mixed nature in which it was used the triangulation of instruments for data collection. The results show that the studied characteristics in fact influence the public entrepreneurship. There is a positive relation to the presence of factors hierarchy, formality, flexibility, autonomy, rewards, expertise, accountability, multiplicity of objectives, results orientation, legal liability and for competition. There is a negative relation to the presence of the factors participation and political influence.

Keywords: Municipal public administration. Public administration. Entrepreneurial orientation. Brazil.

\section{Introdução}

Nos últimos tempos, as ideias tradicionais sobre Gestão Pública vêm sendo alteradas à medida que as velhas formas de governar têm se mostrado ineficientes. A necessidade de alocar melhor os recursos públicos e a necessidade de se obter maior efetividade nos serviços ofertados são pontos que têm urgido por mudanças e o setor público, então, busca maneiras inovadoras para que isso aconteça como consequência das perspectivas da Administração Pública Gerencial.

Nesse sentido, algumas ações baseadas em uma administração estratégica foram introduzidas no setor público. Uma delas é o empreendedorismo que, segundo Hipólito Borges, Romaniello e Brito (2013), também corroborado por Valadares e Emmendoerfer (2015), esteve durante muito tempo ligado principalmente ao setor privado.

Segundo Borins (1998b), Boyett (1996), Drucker (1985) e Osborne e Gaebler (1992), a idealização de governo empreendedor se fundamenta pela promoção de melhores serviços, uma vez que o principal ponto por detrás do empreendedorismo

BORGES, D. A. H.; ROMANIELLO, M. M.; BRITO, M. J. Empreendedorismo no setor público: a influência das características organizacionais. Revista de Empreendedorismo e Gestão de Pequenas Empresas, v.5, n.1, 2016. 
público é encontrar maneiras de oferecer maiores escolhas e benefícios públicos proporcionando serviços de alta qualidade aos cidadãos.

As práticas de empreendedorismo público baseadas no mercado proporcionam um grande número de vantagens e têm papéis importantes a desempenhar na política e na administração pública (BOZEMAN, 2007, p. 7). Deste modo, para o autor, a adoção de práticas empresariais, tais como a busca de oportunidades, de inovação e a proatividade, podem melhorar as capacidades internas e contribuir para valores públicos de sustentabilidade e produtividade. Esta pode ser a melhor maneira para resolver percepções recorrentes de serviços menos eficientes (LLEWELLYN; JONES 2003).

Mesmo diante de tal perspectiva do empreendedorismo, segundo Kim (2010), o foco das pesquisas sobre este tema está voltado apenas para a análise de características psicológicas e comportamentais dos indivíduos o que, para o autor, são iniciativas insuficientes para se entender o cerne do empreendedorismo público como uma ação sistemática para melhorar o desempenho de governar. Assim, poucas pesquisas são conduzidas para tentar propiciar suporte empírico a fim de estimular o empreendedorismo no setor público.

Além disso, o setor apresenta muitas peculiaridades e a aplicação de tópicos de empreendedorismo não pode ser diretamente transportada e incorporada sem uma análise prévia conjuntural. Essas características precisam ser estudadas para que 0 ambiente organizacional favoreça a implementação de ações empreendedoras.

Nesse sentido, Kim (2010) afirma que determinadas características organizacionais-estruturais, administrativas, culturais e ambientais, podem influenciar sobremaneira a implementação do empreendedorismo nas organizações públicas.

No entanto, se de fato essas características organizacionais influenciam a adoção de ações empreendedoras, como essa influência acontece nas organizações públicas? Para encontrar resposta para essa questão, o objetivo central desse trabalho foi analisar a relação entre as características organizacionaisestruturais, administrativas, culturais e ambientais, e o empreendedorismo em organizações públicas.

BORGES, D. A. H.; ROMANIELLO, M. M.; BRITO, M. J. Empreendedorismo no setor público: a influência das características organizacionais. Revista de Empreendedorismo e Gestão de Pequenas Empresas, v.5, n.1, 2016. 


\section{Empreendedorismo em Organizações Públicas}

O empreendedorismo, de acordo com Costa-de-Souza (2013), foi difundido e esteve ligado de forma expressiva ao setor privado, mas com pouca ênfase no setor público. De forma mais específica, o empreendedorismo voltado para este último setor, segundo Diefenbach (2011), tem destaque no âmbito internacional, porém, Morais et al. (2015, p. 28) ressaltam que no Brasil o empreendedorismo no setor público "[..] ainda é bastante incipiente".

De acordo com esses últimos autores, a justificativa para isso pode estar calcada na novidade de governo empreendedor, o que vai de encontro aos pensamentos de Kim (2010), pois atrela o empreendedorismo no setor público ao surgimento da Nova Administração Pública. Segundo este autor, o empreendedorismo está conectado a esse movimento porque tenta remediar, por meio de mecanismos não burocráticos, os problemas da burocracia tradicional.

No Brasil, essa Nova Administração é conhecida como Administração Pública Gerencial e teve seu início no país a partir de 1995, de acordo com BresserPereira (1999). Isso porque, segundo Valadares e Emmendoerfer (2015, p. 83), o processo de modernização que está acontecendo no setor nos últimos anos "tem sido associado a noções comportamentais e gerenciais, imbuídas de conceitos e práticas, que eram próprias e, até então, restritas à esfera das organizações empresariais".

Mas diferentemente dos métodos mercadológicos, o empreendedorismo público tem como finalidade, ampliar e melhorar os serviços ofertados à população. De acordo com Kim (2010):

"[...] o principal ponto por detrás do empreendedorismo público não é fazer um governo de negócios ou que compreenda o mercado, ao invés disso, a ideia do empreendedorismo público é aumentar as oportunidades para a adoção de ideias inovadoras e encontrar maneiras de oferecer mais escolhas e benefícios públicos, proporcionando serviços de alta qualidade aos cidadãos." (KIM, 2010, p. 781).

Assim, para Kim (2010), assim como para Diefenbach (2011), Currie et al. (2008), Morris, Kuratko e Covin (2008) e Kearney, Hisrich e Roche (2007), a vertente 
pública do empreendedorismo deixa de lado a questão estritamente econômica e passa a ser definida em termos de tomada de risco, inovação e proatividade.

Deste mesmo modo, Bozeman (2007) corrobora os pensamentos de Kim (2010), pois considera as oportunidades, a inovação e a habilidade de ser proativo como elementos que podem ampliar as capacidades internas e aumentar a produtividade.

Nesse mesmo sentido, Llewellyn e Jones (2003) percebem nestas três dimensões (tomada de risco, inovação e proatividade) a capacidade de reduzir a ineficiência no serviço público tão recorrente e persistente nesta esfera.

\section{Definições}

O empreendedorismo é visto por alguns autores, como Llewellyn e Jones (2003), Bozeman (2007) e Kim (2010), como uma força potencialmente capaz de modificar e levar as organizações públicas a um nível, de fato, eficiente e eficaz em seus processos. Para outros autores, o empreendedorismo pode ser definido nos seguintes termos. Para Drucker (1985), empreender significa modificar, perceber as necessidades de mudanças e encontrar as soluções necessárias para que isso aconteça. Já Bellone e Goerl (1992) focam na participação. Eles entendem o empreendedorismo como uma ferramenta que possibilita aos cidadãos participar do planejamento público. Morris e Jones (1999), por sua vez, percebem o empreendedorismo como um processo que cria valores para a sociedade.

Na visão de Carpenter (2001), também compartilhada por Roberts e King (1991) e por Roberts (1992), o empreendedorismo é um processo que introduz novas ideias e, portanto, está relacionado ao conceito de inovação. Já para Edwards et al. (2002), o empreendedorismo interliga a sociedade e gestores, pois propõe estratégias que incentivam a participação social. Assim, as pessoas podem auxiliar gestores a identificar as demandas sociais e a propor soluções.

Contudo, de acordo com Stone (1992) e Currie et al. (2008), o empreendedorismo público também é caracterizado por outras duas dimensões, a tomada de risco e a proatividade.

BORGES, D. A. H.; ROMANIELLO, M. M.; BRITO, M. J. Empreendedorismo no setor público: a influência das características organizacionais. Revista de Empreendedorismo e Gestão de Pequenas Empresas, v.5, n.1, 2016. 
Diante dessas definições, entende-se o empreendedorismo como uma ação capaz de fazer com que as organizações públicas se tornem mais inovadoras, proativas e que tomem decisões conscientes. Portanto, o empreendedorismo neste artigo é definido em termos de tomada de decisão, inovação e proatividade.

Definido sob essas três dimensões, torna-se então necessário expor as qualificações do empreendedorismo.

\section{Dimensões}

A tomada de decisão envolve a escolha, a opção que o gestor público faz entre tomar uma ou outra decisão diante do uso do dinheiro público e por isso, segundo Kim (2010), pressupõe decisões conscientes, mesmo perante as incertezas de resultados.

A inovação significa, para Keys (1988, p. 62), "reestruturar os conceitos existentes", proporcionando a criação de outras realidades. Para Morris e Kuratko (2002), é algo que abrange desde a promoção de novas ideias nas tarefas ao desenvolvimento de novos serviços. Kim (2010) corrobora os pensamentos de Morris e Kuratko ao defini-la como uma disposição para adotar novos serviços e reestruturar os processos administrativos.

Quanto à proatividade, Lumpkim e Dess (2001) alegam que esta dimensão se resguarda no aumento da iniciativa a fim de, conforme dito por Morris e Kuratko (2002), tentar antecipar questões futuras. Isso, segundo Kim (2010), faz com que as organizações públicas deixem de agir de forma passiva e passem não só a antever os problemas como a estar em alerta para as novas oportunidades.

Desta forma, o significado de empreendedorismo público é a junção destas três dimensões promovidas institucionalmente em que os gestores devem escolher conscientemente para onde destinar os recursos públicos aproveitando as oportunidades e buscando novos recursos, empregando-os em ideias inovadoras que possam ampliar e melhorar a qualidade dos serviços públicos. 
As Características Organizacionais: características estruturais

Dentre as características presentes nas organizações, a hierarquia, a formalização e a flexibilidade são listadas por Kim (2010) como atributos pertencentes à estrutura que influenciam a adoção de ações empreendedoras.

De acordo com Moon (1999), a hierarquia é um fator que promove a morosidade dos processos que inicia desde a demora nas comunicações até a inibição para adotar ideias inovadoras. Portanto, muitos níveis hierárquicos nas organizações públicas podem diminuir a implementação de práticas empreendedoras.

A formalização, por sua vez, é entendida por Hall (1996) como os procedimentos normalmente previstos em manuais e regulamentos. Isso, segundo Ingram e Clay (2000), força os servidores públicos a ficarem presos às regras diminuindo a autonomia das decisões, a adoção de novas ideias e mesmo a proatividade. Desta forma, quanto maior o grau de formalização mais difícil será adotar o empreendedorismo.

Já a flexibilidade é vista por Kim (2010) como a facilidade em se adaptar às mudanças. Logo, uma organização flexível pode conseguir aproveitar melhor as oportunidades que surgem. Por conseguinte, quanto mais flexível, mais fácil será implementar o empreendedorismo nesta organização.

Desta forma, a presença de muitos níveis hierárquicos e de muita formalização não favorece o empreendedorismo. No entanto, a presença do atributo flexibilidade favorece a implementação do empreendedorismo.

\section{Características Administrativas}

Das características administrativas colocadas por Kim (2010), estão a autonomia, a participação dos servidores na tomada de decisão, a presença de recompensas baseadas no desempenho e a especialização dos servidores.

A autonomia, de acordo com Lumpkin e Dess (2001), é a ação independente quanto a uma decisão. Para Kim (2010), essas decisões se referem aos 
procedimentos rotineiros e administrativos que agilizam os processos das organizações públicas. Deste modo, quanto mais autonomia as organizações promovem, maior será o incentivo em tomar decisões e a adotar ações proativas, características do empreendedorismo.

Já a participação dos servidores na tomada de decisão é vista positivamente sob dois aspectos. Para Rainey e Bozeman (2000), aumenta a satisfação dos servidores, pois estes se sentem mais importantes. Para Andrews et al. (2007), este envolvimento auxilia os gestores na tomada de decisão, já que os servidores detêm o conhecimento prático. Logo, possibilitar a participação é algo que facilita o empreendedorismo público.

Nesse mesmo sentido, recompensar os servidores com base em seus bons desempenhos, seja financeiramente ou não, de acordo com Kim (2010), estimula-os a adotar ações inovadoras e proativas possibilitando o empreendedorismo.

Quanto à especialização, Kim (2010) diz que os servidores especializados tendem a reconhecer a necessidade de mudança e a ser menos resistentes em relação a elas e, portanto, tomam decisões empreendedoras. Nota-se assim, que todos os aspectos apresentados da característica administrativa têm relação positiva com o empreendedorismo público.

\section{Características Culturais}

Dos fatores que compõe as características culturais, três são apresentados como fortes influenciadores do empreendedorismo. São eles: a accountability, a presença de múltiplos objetivos e a orientação para resultados (KIM, 2010). A accountability é entendida por Tinoco (2002), como a responsabilização dos gestores em prestar contas à sociedade dos atos praticados e por isso faz com eles tomem decisões conscientes buscando alocar melhor os recursos públicos.

No entanto, Kim (2010) coloca a multiplicidade de objetivos como um atributo negativo ao empreendedorismo. Isso porque, segundo ele, essa diversidade acaba proporcionando uma divergência de buscas em que cada um tenta atingir um propósito. Isso não leva a um direcionamento claro para a tomada de decisão. 
Já a orientação para resultados está atrelada ao objetivo da organização e, segundo Bozeman (2007), deve ser focalizada no valor público. Se a organização foca neste propósito, todo o seu processo está voltado para o fim e não mais para as etapas intermediárias. Assim, os processos administrativos se tornam mais desburocratizados, porque a busca final é o bem-estar do cidadão.

Portanto, dos três fatores elencados, apenas a multiplicidade dos objetivos é percebida pelos autores como um fator negativo ao empreendedorismo público.

\section{Características Ambientais}

Os ambientes externos são percebidos por autores como Davidsson, Low e Wright (2001), como implicadores diretos na atuação das organizações. Kim (2010) estende esses efeitos para o setor público quando do empreendedorismo. Dentre essas características, estão a influência política, a responsabilidade legal e a competição.

De acordo com Nutt (2006), o ambiente político exerce uma influência crítica na administração pública, isso porque, uma organização sob alto grau de influência está sujeita a um maior controle por autoridades políticas (KIM, 2010). Destarte, uma maior influência limita o empreendedorismo público, pois as decisões são tomadas levando-se em consideração os interesses políticos de outros agentes envolvidos.

A responsabilidade legal, para Bovens (2005), são práticas utilizadas para controlar as atividades administrativas e financeiras das organizações. Devido a isto, os gestores tendem a evitar as ações inovadoras (KIM, 2010). Logo, quanto maior a responsabilidade legal mais difícil será implementar o empreendedorismo.

Quanto à competição, Morris e Jones (1999) e Kim (2010) a percebem como uma característica que pode levar, não à disputa no setor público, mas à motivação. Seria uma forma de se espelhar em organizações públicas bem-sucedidas e assim, melhorar a qualidade dos serviços públicos. Então, quanto maior a percepção de competição, mais facilmente o empreendedorismo será implementado.

Ante o exposto, percebe-se que a hierarquia, a formalização, a influência política e a responsabilidade legal, quando presentes de forma substancial na 
organização, são fatores que apresentam uma relação inversa ao empreendedorismo público. Conquanto, existe uma relação positiva dos quesitos flexibilidade, autonomia, participação nas tomadas de decisão, existência de recompensas baseadas no desempenho, especialização, presença da accountability, direcionamento para resultados e competição percebida.

Nessa linha, percebe-se, diante do que foi explicitado, que a idealização de o empreendedorismo estar ligado somente ao indivíduo deixa de existir passando a ser considerado também o incentivo por parte das organizações, em que as características organizacionais têm peso significativo. Para autores como Valadares e Emmendoerfer (2015), o comportamento empreendedor pode ser impulsionado pela própria organização, constituindo o que se denomina de empreendedorismo corporativo.

No empreendedorismo público, a cultura organizacional se torna então preponderante em relação ao comportamento empreendedor individual. No entanto, não são pontos excludentes, mas inter-relacionados. Isso porque, individualmente, não é possível adotar ações empreendedoras, principalmente porque o ambiente público pressupõe coletividade, logo, todos devem ser e estar envolvidos. Isso tornase praticamente impossível sem o incentivo da própria organização pública.

Portanto, as características organizacionais influenciam sobremaneira a implantação do empreendedorismo no setor público.

\section{Procedimentos Metodológicos}

O presente estudo trata-se de uma pesquisa exploratória que utilizou como estratégia, o estudo de caso. De acordo com Cooper e Schindler (2003, p. 120), o estudo de caso permite colocar "mais ênfase em uma análise contextual [...] e [...] pode ser a fonte de novas hipóteses e constructos".

Godoy (1995) por sua vez, considera que esse estudo tem como propósito analisar intensivamente uma unidade social e Yin (2001, p. 21) evidencia que "o estudo de caso permite uma investigação para se preservar as características holísticas e significativas dos eventos da vida real". 
Diante do exposto, o estudo de caso se apresentou como uma boa estratégia de pesquisa para este trabalho, sendo realizado com os servidores de uma organização pública de nível municipal, mais especificamente em uma Prefeitura Municipal localizada na região sudeste de Minas Gerais.

A escolha da organização foi motivada pela transição de gestão que ocorreu neste município em setembro de 2014. Este fato poderia ser relevante ao estudo do empreendedorismo já que houve a substituição do gestor público, dos secretários municipais e o deslocamento de vários servidores efetivos para outros órgãos.

\section{Técnica de Coleta de Dados}

Inicialmente, utilizou-se o questionário como instrumento de coleta de dados. Segundo Gil (1999, p. 128), o questionário é uma técnica que objetiva levantar "o conhecimento de opiniões [...], expectativas, situações vivenciadas, etc.". O modelo de questionário utilizado foi o estruturado (survey), apropriado para pesquisas que pretendem obter opiniões de determinado grupo, objetivando levantar informações quantitativas a respeito de uma determinada população (FREITAS et al., 2000).

Para a construção das questões foi utilizada a escala tipo Likert ${ }^{4}$ de cinco pontos. Esta escala é a mais adequada, pois é mais precisa e completa que a de três pontos e mais ágil do que a de sete (DALMORO; VIEIRA, 2013).

Os questionários foram utilizados para coletar dados quantitativos, sendo aplicados a 86 servidores detentores de cargos "comissionados". A escolha destes servidores se deu porque estes cargos são destinados às atribuições de direção, chefia e assessoramento, conforme artigo 37, inciso $V$ da Constituição Federal de 1988 que, em tese, possuem autonomia e estão inseridos nas tomadas de decisões e, portanto, estariam mais aptos a relatar sobre os fatores do empreendedorismo público no caso estudado.

\footnotetext{
${ }^{4}$ A escala Likert foi proposta por Rensis Likert em 1932. Seu uso é indicado quando se pretende medir atitudes, pois compreende afirmações relacionadas ao objeto pesquisado. Para estas questões os respondentes informam o seu grau de concordância ou discordância e para cada resposta é atribuído um peso que reflete a direção da atitude.
}

BORGES, D. A. H.; ROMANIELLO, M. M.; BRITO, M. J. Empreendedorismo no setor público: a influência das características organizacionais. Revista de Empreendedorismo e Gestão de Pequenas Empresas, v.5, n.1, 2016. 
No entanto, no decorrer da pesquisa sentiu-se a necessidade de aprofundar os estudos através de métodos qualitativos que propiciassem maior conhecimento sobre o grupo estudado e que pudessem auxiliar na análise dos dados quantitativos. Para tanto, optou-se pela entrevista com uso do roteiro semiestruturado, uma ferramenta de qualidade para se coletar dados (BELEl et al., 2008). Foram realizadas 3 entrevistas com dois secretários e um controlador escolhidos por conveniência.

Também foi utilizada a observação participante, tendo como princípio, "integrar o observador à sua observação" (QUEIROZ et al., 2007, p. 278). A observação aconteceu com introdução do pesquisador na prefeitura estudada. Essa inserção aconteceu através da nomeação de um dos pesquisadores para um determinado cargo a fim de não comprometer a coleta dos dados devido à entrada de uma pessoa que não faz parte da realidade em estudo e que estaria avaliando os comportamentos dos servidores.

Durante a permanência, todos os dados considerados relevantes, tais como opiniões e vivência de servidores e secretários, decisões e procedimentos eram anotados em diário de campo. Desta maneira, foi utilizada a triangulação de instrumentos para a coleta de dados.

\section{Técnica de Análise de Dados}

Para analisar os dados quantitativos, o presente estudo valeu-se de análises estatísticas utilizando, para tanto, o software estatístico SPSS Statistics 17.0 (Statistical Package for the Social Science). Foram realizadas as seguintes análises:

- Descritiva: utilizou-se a frequência, a porcentagem e a média de todas as variáveis consideradas na pesquisa;

- Correlação: utilizou-se a técnica de crosstabs para analisar a relação entre variáveis.

Para cada nível de concordância da escala Likert ${ }^{1}$ foi atribuído um peso, que variou entre os valores de 1 a 5 e um significado que pode ser assim definido: 
(Peso 1) Discordo Totalmente: significa que a prefeitura em estudo não possui o atributo central da afirmativa.

(Peso 2) Discordo: significa que o atributo central da afirmativa é percebido raramente na prefeitura pelo entrevistado, ou seja, não se aplica o mencionado atributo em sua maioria.

(Peso 3) Indeciso: significa que o respondente não sabe, não quis responder ou ficou dividido quanto à concordar ou discordar, o que pode indicar que às vezes os atributos são percebidos e outras vezes não.

(Peso 4) Concordo: significa que o atributo central da afirmativa é percebido pelos respondentes parcialmente, ou seja, tal atributo existe mas não está totalmente constituído na prefeitura em estudo.

(Peso 5) Concordo Totalmente: significa que o atributo central da afirmativa está totalmente presente na prefeitura em estudo.

Desta forma, tendo-se como valor médio o peso 3 , as médias das variáveis estudadas que ficaram acima deste valor tendem à "concordância" e para as que ficaram abaixo, tendem à "discordância".

Para o cálculo da média $(\mathrm{M})$ de cada variável, foi utilizada a frequência ( $\mathrm{f}$ ) absoluta, o peso atribuído ( $p$ ) e o total da amostra (t) onde: $(M=f \times p / t)$, ou seja, para cada variável, multiplicou-se a frequência individual de cada nível de concordância por seu respectivo peso conforme distribuído acima. O somatório do resultado dessa multiplicação foi divido pelo total da amostra. Esse método foi retirado de Cartoni (2015).

Contribuindo para o entendimento das análises quantitativas, foram utilizadas as entrevistas bem como os relatos e observações anotados no diário de campo. Assim, para cada variável, foi comparado os dados quantitativos com os qualitativos.

\section{Resultados e Discussões - Perfil dos Entrevistados}

A presente pesquisa foi realizada com 86 servidores que detinham os cargos de Coordenadores (4,7\%), Assessores (27,9\%), Chefes de Divisão (15,1\%), Chefes 
de Departamento (31,4\%), Chefe de Gabinete (1,2\%), Gerentes (8,1\%), Ouvidor $(1,2 \%)$, Assessor Jurídico (1,2\%), Secretários Municipais $(8,1 \%)$ e Controlador $(1,2 \%)$. Destes, $61,6 \%$ ocupam apenas os cargos comissionados e $38,4 \%$ são servidores efetivos que possuem cargos na prefeitura.

A maioria dos respondentes é do sexo feminino $(54,7 \%)$ e a minoria do sexo masculino (45,3\%), com faixa etária que varia da seguinte maneira: entre 18 e 25 anos (9,3\%), 26 a 30 anos (11,6\%), 31 a 35 anos (22,1\%), 36 a 40 anos (12,8\%) e acima de 41 anos (44,2\%).

Quanto ao tempo de trabalho na prefeitura, os respondentes se distribuem assim: há menos de 1 ano (40,7\%), de 1 a 3 anos (10,5\%), de 3 a 7 anos (8,1\%) e acima de 7 anos (40,7\%).

Fazendo uma análise de correlação, é possível perceber que os entrevistados que trabalham há menos de 1 (um) ano detém apenas a característica de comissionado (39,5\% dos entrevistados) e os que estão acima de 7 (sete) anos são efetivos com cargo em comissão (31,4\% dos entrevistados).

Logo, pode-se dizer que os perfis dos entrevistados são de pessoas mais velhas, acima de 41 (quarenta e um) anos de idade, que trabalham há menos de 1 (um) ano na instituição e ocupam cargos em comissão apenas.

\section{O Empreendedorismo na Organização Pública Estudada}

Para avaliar o empreendedorismo, foi solicitado aos respondentes que informassem o grau de concordância/discordância quanto a duas afirmações. A primeira definiu o empreendedorismo no setor público em termos de tomada de decisão, inovação e proatividade, e a segunda, sobre o nível empreendedor da prefeitura.

Quanto à definição, 91,9\% dos respondentes concordaram com a afirmação apresentada (47,7\% concordaram parcialmente e 44,2\% concordaram totalmente). A média para essa variável foi de 4,29, o que reflete a direção da atitude para a concordância.

BORGES, D. A. H.; ROMANIELLO, M. M.; BRITO, M. J. Empreendedorismo no setor público: a influência das características organizacionais. Revista de Empreendedorismo e Gestão de Pequenas Empresas, v.5, n.1, 2016. 
Para a segunda afirmação, 45,3\% concordaram que a Prefeitura é empreendedora. Destes, 39,5\% concordaram parcialmente. Contra esta afirmação, $34,9 \%$ dos entrevistados discordaram. Destes, 27,9\% discordaram parcialmente.

Isso indica que a característica empreendedora é percebida pelos entrevistados, porém não em sua totalidade. $O$ atributo está presente, mas não está totalmente constituído nesta prefeitura. Essa percepção pode estar relacionada a ações individuais pelas quais uns se mostram mais proativos que outros, geram ações empreendedoras. No entanto, isso não é promovido pelos demais servidores e gestores, logo, a "máquina" administrativa como um todo tende a apresentar falhas.

Em um dos relatos de campo, o Respondente 1 disse que prefeitura apresenta características empreendedoras e que a maioria dos gestores promovem ações nesse sentido, contudo, falta o envolvimento e essa percepção aos demais gestores. Nas palavras desse Respondente: "se ela não é empreendedora de fato, pelo menos ela está tentando ser".

A média para esta variável foi de 3,09, indicando para a direção da concordância. Todavia, o fato da maioria concordar parcialmente indica que algumas características podem estar ausentes. Assim, entendendo a prefeitura estudada como empreendedora, foi possível levantar os atributos que a definem como tal e encontrar como essas características organizacionais influenciam o empreendedorismo público.

\section{Das Características Estruturais}

De acordo com Kim (2010), quatro variáveis pertencentes à estrutura organizacional são influenciadores do empreendedorismo público: a hierarquia, a formalização e a flexibilidade.

Para Moon (1999), a hierarquia é um fator que corrobora para a morosidade dos processos e inibe a adoção de ideias inovadoras, já que o fato de ter que passar por vários superiores além de ocasionar a demora, também retrai as ações dos servidores em face do receio de tê-la questionada ou recusada. Logo, a presença de 
muitos níveis hierárquicos nas organizações públicas poderia diminuir a implementação de práticas empreendedoras. Para esta variável, $80,2 \%$ dos entrevistados (média de 3,84 na concordância) afirmaram que essa presença é notada dentro da prefeitura.

Em um dos relatos anotados em diário de campo, um entrevistado, denominado de Entrevistado 1, afirmou que não considera a hierarquia como um fator que impossibilita as ações empreendedoras, pelo contrário, ela, de certa forma, força o planejamento, já que um processo deve obedecer à sequência dos níveis até que seja concluído. Em função desse tempo, as pessoas se tornariam mais proativas. Além disso, o fato de possuir o respaldo de todos os envolvidos faz com que as pessoas se sintam mais confiantes quando da conclusão de cada etapa.

Considerando que esta instituição pública é empreendedora do ponto de vista dos respondentes, essa característica fugiria ao que foi proposto por Kim (2010) e ao que foi dito por Moon (1999), de que a presença de muitos níveis hierárquicos trabalha inversamente ao empreendedorismo público.

Quanto à formalização, definida por Hall (1996) como sendo os procedimentos escritos, colocados em papel, 79,1\% dos entrevistados (média de $3,79)$ concordaram que existe muita formalidade nos procedimentos internos.

Essa característica, segundo Ingram e Clay (2000), força os servidores públicos a ficarem presos em cumprir regras, diminuindo a adoção das ideias inovadoras e mesmo a proatividade, pois de nada adiantaria uma ação empreendedora, já que o processo envolve muitas pessoas. Desta forma, quanto maior o grau de formalidade, mais difícil seria adotar o empreendedorismo.

Entretanto, em relato, o Entrevistado 2 disse que a existência dessa variável vai além do empreendedorismo, trata-se de um quesito praticamente obrigatório no setor público. Isso porque as atividades realizadas na gestão pública envolvem vários setores, logo, faz-se necessário que os procedimentos internos sejam devidamente oficializados a fim de que siga o fluxo correto. Nesta mesma conversa, o Entrevistado mencionado enfatizou as especificidades da Administração Pública, como solicitações, licitação, empenho, contratação e pedidos que devem ser seguidos criteriosamente.

Corroborando para essa questão, o Entrevistado 3 afirmou o seguinte: 


\begin{abstract}
"Eu acho que a normatização é fundamental. Se você não criar normas, se você não colocar normas no serviço público você vai ver o serviço desandar e vai... aí você vê um controle mais rígido né a aí a equipe técnica ela é mais eficiente porque a equipe técnica ela vai ver esse aspecto ele vai ver o aspecto técnico ele não vai ver o aspecto político né então assim a normatização, o fluxo normal né, você criar fluxogramas para poder agilizar o trabalho ele é fundamental. Agora a burocracia ela tem que existir. Primeiro porque você criar normas você tá burocratizando o trabalho você não pode é fazer com que a burocracia vire uma coisa de empecilho ela tem que existir para colocar regras, colocar normas para criar um fluxo e aí sim você ter uma sequência de, fazer a engrenagem funcionar".
\end{abstract}

Quando questionado se a normatização e a formalidade reduzem o empreendedorismo público, o Entrevistado 3 assim se posicionou:

\footnotetext{
"Não, não eu acho que não. Porque é o que eu te falei. Se você tiver uma base formada, essa normatização, pra você ter essa base, além do corpo técnico que eu falei você precisa ter o fluxo, você precisa ter as normas pra você poder trabalhar.".
}

Nesse sentido, a variável formalidade, vista por Ingram e Clay (2000) como inibidora do empreendedorismo, foi percebida pelos entrevistados como necessária dentro da prefeitura.

No que diz respeito à flexibilidade, Kim (2010) afirma que as organizações que se adaptam mais facilmente às mudanças, tanto do ambiente interno quanto as provocadas pelo ambiente externo, tendem a ser mais inovadoras, pois conseguem explorar as oportunidades mesmo diante das adversidades. Por isso, instituições públicas flexíveis são mais empreendedoras.

No que tange ao ambiente interno, 65,2\% dos respondentes discordaram que a prefeitura consegue se adaptar com facilidades às mudanças internas. 54,7\% discordaram parcialmente. A média para essa variável foi de 2,52, o que indica a tendência da discordância.

Quanto às mudanças provocadas pelo ambiente externo, 57\% discordaram que ela consegue se adaptar com facilidade. Destes, $50 \%$ discordaram parcialmente. A média da variável foi de 2,60.

$O$ fato de ser percebida parcialmente significa que a flexibilidade se faz presente em alguns momentos, não em todos. Porém, esta é uma variável que deve ser analisada um pouco mais a fundo.

BORGES, D. A. H.; ROMANIELLO, M. M.; BRITO, M. J. Empreendedorismo no setor público: a influência das características organizacionais. Revista de Empreendedorismo e Gestão de Pequenas Empresas, v.5, n.1, 2016. 
Em relato, o Entrevistado 3 afirmou que a prefeitura sofre mudanças frequentemente. Isso, de acordo com ele, ocorre porque as leis e as normas estão sempre sendo alteradas e, à medida que há uma alteração legal, as prefeituras são obrigadas a se adaptarem à nova realidade, logo, a flexibilidade tem que existir.

Por outro lado, o Entrevistado 3 afirmou que essas mudanças são sempre "sofridas" em face do pouco tempo para a adaptação, da falta de auxílio dos órgãos externos e pela resistência das próprias pessoas. Logo, a adaptação às mudanças não só existe como é essencial na Administração Pública. Contudo, a facilidade de adaptação é que se faz ausente.

Diante das três variáveis analisadas, pertencentes às características estruturais, pode-se chegar à seguinte proposição:

QUADRO 1 - CARACTERÍSTICAS ESTRUTURAIS DO EMPREENDEDORISMO
NO SETOR PÚBLICO
\begin{tabular}{|l|c|c|}
\hline \multirow{2}{*}{$\begin{array}{c}\text { CARACTERISTICAS } \\
\text { PRESENTES }\end{array}$} & FAVORECE O EMPREENDEDORISMO PÚBLICO \\
\cline { 2 - 3 } & Na literatura & Para os entrevistados \\
\hline Hierarquia & Não & Sim \\
\hline Formalidade & Não & Sim \\
\hline Flexibilidade & Sim & Sim \\
\hline
\end{tabular}

FONTE: Os autores (2016).

Portanto, dos fatores analisados da característica estrutural, apenas a flexibilidade é percebida pelos entrevistados no mesmo sentido dos estudiosos do empreendedorismo. Diferentemente da literatura, os fatores hierarquia e formalidade são entendidos não como um entrave, mas como um item necessário dentro das instituições públicas, sendo possível empreender com a presença deles.

\section{Das Características Administrativas}

Dentre os fatores relacionados à característica administrativa colocados por Kim (2010), estão a autonomia, a participação dos servidores na tomada de decisões, a presença de recompensas baseadas no desempenho e a especialização.

Quanto a autonomia, 74,4\% dos entrevistados (média de 2,30) discordaram que podem tomar todas as decisões sem consultar o seu chefe imediato. Destes, 
53,5\% discordaram parcialmente. Em relatos, o Entrevistado 1 afirmou que dentro das suas competências, quando a questão é administrativa, rotineira, ele pode tomar decisões, entretanto, as que podem repercutir de alguma forma devem ser repassadas ao superior imediato. Contribuindo com o relato, o Entrevistado 2 disse que uma maior autonomia iria contribuir para acelerar os processos e a prestação do serviço público ao cidadão já que as decisões poderiam ser tomadas tecnicamente sem precisar aguardar o retorno de outros níveis estratégicos.

Para os autores do empreendedorismo, como Lumpkin e Dess (2001), a autonomia é vista como um atributo que possibilita aos servidores tomar decisões quanto a assuntos rotineiros, o que aceleraria os procedimentos internos e reduziria, consequentemente, a demora atrelada à presença de muitos níveis hierárquicos. Assim, na percepção dos entrevistados, a presença desta característica na prefeitura iria influenciar positivamente a adoção de ações inovadoras.

Quanto a participação, $76,8 \%$ dos respondentes discordaram que os servidores não comissionados participam das tomadas de decisão. Nos relatos, o Respondente 1 afirmou que na sua área é muito difícil ter a participação de todos, porque se trata de assuntos muito específicos e quem não está envolvido diretamente teria grandes dificuldades para opinar sobre a matéria. Contribuindo com esse relato, o Entrevistado 1 disse que outra grande dificuldade está atrelada aos recursos orçamentários e, principalmente, financeiros, pois muitas vezes as pessoas que não estão ligadas diretamente não entendem a escassez dos recursos, o que dificultaria chegar a um ponto comum e tomar a decisão.

Desta forma, a percepção dos entrevistados não vai de encontro ao que é dito por Andrews et al. (2007), de que a participação auxiliaria os gestores na tomada de decisão. Para essa variável, a média tendendo a discordância foi de 2,09.

No que tange às recompensas, Kim (2010) diz que as instituições que recompensam os servidores, seja financeiramente ou não, pelo bom desempenho tendem a incentivar a adoção de ações proativas, pois criam a expectativa de retorno quando um trabalho é bem desempenhado e reconhecido. Para $73,3 \%$ dos entrevistados, a prefeitura não trabalha com recompensas para o servidor. Destes, $41,9 \%$ discordaram totalmente. A média que direciona a discordância foi de 1,97.

BORGES, D. A. H.; ROMANIELLO, M. M.; BRITO, M. J. Empreendedorismo no setor público: a influência das características organizacionais. Revista de Empreendedorismo e Gestão de Pequenas Empresas, v.5, n.1, 2016. 
Contudo, em entrevista realizada, o Entrevistado 2 disse que uma prefeitura empreendedora é aquela que trabalha focada em três vetores:

"[...] o vetor funcional que é o potencial humano, o vetor de qualidade que é o vetor da eficiência e da eficácia e o vetor do cliente externo que na realidade, é a própria população. [...]".

Nesse sentido, ele afirma que para trabalhar o vetor humano é necessário ter o processo de recompensas:

"Claro que tem que ter o processo por produtividade, fulano ganha mais que beltrano porque o fulano trabalha mais, ele me dá mais resultado, na iniciativa privada é assim, claro que tem que ser assim".

Logo, entende-se que as recompensas são percebidas como um fator que favorece o empreendedorismo, como afirma Kim (2010).

No que diz respeito à especialização, 53,5\% dos respondentes discordaram de que, de maneira geral, os servidores possuem competência técnica para ocupar os cargos em que se encontram. A média para a direção da discordância foi de 2,30. De acordo com o Entrevistado 3, ter um corpo técnico especializado é um dos fatores mais importantes para o empreendedorismo, uma vez que são essas pessoas que fazem, na prática, o processo acontecer. Quando indagado sobre as características que uma prefeitura deve ter para ser empreendedora a resposta foi a que segue:

"Diminuir o cargo político e colocar o cargo técnico, isso é fundamental. [...] se você tem um corpo técnico mais preparado, mais capacitado, ele vai ter uma base para ser esse Prefeito empreendedor. A... a demanda que existe né... a população... a demanda que a população exige... exige da Administração ela requer mais rapidez né [...] pra ser mais ágil, ser mais assim, pontual, ser mais eficiente, então a... o corpo técnico ele tem que ser técnico".

Nesse sentido, Kim (2010) acredita que os servidores especializados, por serem mais técnicos e possuir o conhecimento relativo à área, tendem a ser menos resistentes em relação às mudanças e a ser mais proativos e, portanto, mais adeptos a tomar atitudes empreendedoras que conduzem à prestação de um serviço público mais eficiente, opinião esta corroborada pelos entrevistados. 
Diante da análise destas quatro variáveis, as quais são pertencentes às características administrativas, pode-se chegar à seguinte proposição expressa abaixo:

\section{QUADRO 2 - CARACTERÍSTICAS ADMINISTRATIVAS DO EMPREENDEDORISMO NO SETOR PÚBLICO}

\begin{tabular}{|l|l|l|}
\hline \multirow{2}{*}{$\begin{array}{c}\text { CARACTERÍSTICAS } \\
\text { PRESENTES }\end{array}$} & \multicolumn{2}{|c|}{ FAVORECE O EMPREENDEDORISMO PÚBLICO } \\
\cline { 2 - 3 } & Naiteratura & Para os entrevistados \\
\hline Autonomia & Sim & Sim \\
\hline Participação & Sim & Não \\
\hline Recompensas & Sim & Sim \\
\hline Especialização & Sim & Sim \\
\hline
\end{tabular}

FONTE: Os autores (2016).

Como pode ser visualizado no Quadro 2, dos fatores pertencentes da característica administrativa, a participação é o único que os entrevistados não entendem como facilitador do empreendedorismo, pelo contrário, ela é vista como algo que pode atrasar e dificultar a tomada de decisão, principalmente por causa da dificuldade de se chegar a uma posição única e pela falta de conhecimento de quem não está envolvido diretamente. No entanto, a presença de autonomia, recompensas pelo bom desempenho e a especialização/competência técnica dos servidores são percebidos como fatores que contribuem positivamente para o empreendedorismo.

\section{Das Características Culturais}

Dos fatores culturais elencados por Kim (2010), três são apresentados como fortes influenciadores do empreendedorismo no setor público: a accountability, a presença de múltiplos objetivos e a orientação para resultados.

A accountability, termo traduzido como responsabilização, indica que os gestores públicos estão obrigados a prestar contas dos resultados obtidos, logo, revela-se como uma variável estimuladora de decisões conscientes, premissa do empreendedorismo no setor público (TINOCO, 2002).

Para esta variável, foi afirmado aos respondentes que o prefeito tem a obrigação de prestar contas de todos os atos públicos tanto à população quanto aos órgãos de controle externo. Neste caso, 94,2\% concordaram com a afirmação,

BORGES, D. A. H.; ROMANIELLO, M. M.; BRITO, M. J. Empreendedorismo no setor público: a influência das características organizacionais. Revista de Empreendedorismo e Gestão de Pequenas Empresas, v.5, n.1, 2016. 
sendo que $60,5 \%$ concordaram totalmente. A média que apresenta essa direção foi de 4,47 .

Em relatos do Entrevistado 3 e do Respondente 1, a responsabilização é vista como um fator necessário no setor público, assim como a normatização, pois é um dos fatores que difere o público da iniciativa privada porque o gestor tende a tomar decisões mais conscientes em face do controle externo.

Quanto à multiplicidade de objetivos, Kim (2010) classifica como uma variável negativa ao empreendedorismo, pois não direciona a instituição pública ao seu propósito maior. Assim, cada servidor está buscando uma meta, dificultando a tomada de decisão. Para este atributo, 73,2\% dos respondentes, afirmaram que a prefeitura possui grande diversidade de objetivos. Em relatos, o Respondente 2 e o Respondente 1 disseram que essa diversidade é inerente à Administração Pública, pois a população carece de muitos serviços. Além disso, de acordo com eles, esses objetivos são específicos e que, se somados, tornam-se o objetivo maior da prefeitura que é o bem-estar do cidadão. A média de tendência a concordância foi de 3,73. Assim, a multiplicidade ou diversidade de objetivos é encarada pelos respondentes de maneira diferente da proposta por Kim (2010).

Quanto à orientação para os resultados, apontada no setor público por Bozeman (2007) como a orientação focalizada no valor público, teve a concordância de $43 \%$ dos respondentes. Ou seja, para eles, a prefeitura trabalha voltada para os resultados que deseja obter, isso faz com que as pessoas trabalhem juntos em prol do mesmo fim. Logo, este é um fator que favorece o empreendedorismo, de acordo com os respondentes.

Nesse sentido, as três variáveis analisadas para as características culturais podem ser expostas na seguinte proposição:

QUADRO 3 - CARACTERÍSTICAS CULTURAIS DO EMPREENDEDORISMO
NO SETOR PÚBLICO
\begin{tabular}{|l|c|c|}
\hline $\begin{array}{l}\text { CARACTERISTICAS } \\
\text { PRESENTES }\end{array}$ & FAVORECE O EMPREENDEDORISMO PÚBLICO \\
\cline { 2 - 3 } & Na literatura & Para os entrevistados \\
\hline Accountability & Sim & Sim \\
\hline $\begin{array}{l}\text { Multiplicidade de } \\
\text { Objetivos }\end{array}$ & Não & Sim \\
\hline $\begin{array}{l}\text { Orientação para } \\
\text { Resultados }\end{array}$ & Sim & Sim \\
\hline
\end{tabular}

FONTE: Os autores (2016).

BORGES, D. A. H.; ROMANIELLO, M. M.; BRITO, M. J. Empreendedorismo no setor público: a influência das características organizacionais. Revista de Empreendedorismo e Gestão de Pequenas Empresas, v.5, n.1, 2016. 
Dos fatores relativos à característica cultural, todos foram compreendidos pelos entrevistados como itens que podem favorecer o empreendedorismo, inclusive o fato de a prefeitura possuir muitos objetivos, o que na literatura é exposto como um fator negativo à adoção de ações empreendedoras. Para os respondentes terem objetivos menores ou apenas um objetivo é indiferente ao empreendedorismo, uma vez que tudo levará ao objetivo único de prestar serviços públicos ao cidadão.

\section{Das Características Ambientais}

Dentre os fatores ambientais, a influência política, a responsabilidade legal e a competição são expostas por Kim (2010) como fatores que influenciam o empreendedorismo.

De acordo com Nutt (2006), o ambiente político acaba influenciando criticamente a Administração Pública, pois as decisões são tomadas levando-se em consideração os interesses políticos de determinados grupos, e não em função das demandas da população. Por isso, este é um fator entendido por muitos autores que desfavorece o empreendedorismo público. Para $74,4 \%$ dos respondentes, as decisões tomadas pelos gestores da prefeitura sofrem influência política. A média que direciona à concordância foi de 3,78.

Contudo, de acordo com os relatos do Respondente 3, as decisões deveriam ser tomadas tendo exclusivamente por base, as necessidades da população. Também se pronunciou o Respondente 2 quanto a essa variável. Para ele, que é efetivo e passou por quatro gestões, a influência política é algo que prejudica a população porque nunca se sabe se a decisão foi tomada porque alguém pediu, ou se para benefício próprio ou se por demanda da sociedade. Logo, nem sempre uma decisão tomada será consciente e se revelará como uma ação empreendedora. Desta forma, os relatos demonstram a negatividade da influência política quanto ao empreendedorismo.

No que tange à responsabilidade legal, colocada por Bovens (2005) como as práticas legais utilizadas para controlar as atividades administrativas e financeiras das organizações e compreendida por Kim (2010) como um fator limitante ao

BORGES, D. A. H.; ROMANIELLO, M. M.; BRITO, M. J. Empreendedorismo no setor público: a influência das características organizacionais. Revista de Empreendedorismo e Gestão de Pequenas Empresas, v.5, n.1, 2016. 
empreendedorismo, já que gestores tendem a evitar as ações inovadoras com receio das sanções legais, $79 \%$ dos respondentes disseram que o prefeito e os agentes públicos respondem legalmente por todos os atos públicos. A média que representa essa direção foi de 4,06 . No entanto, nos relatos colhidos, a maioria das pessoas se pronunciou no mesmo sentido das variáveis accountability e normatização, de que se trata de um fator essencial à Administração Pública. Essas três variáveis, na visão dos respondentes, são as responsáveis pelo cuidado do gestor público quanto aos seus atos e decisões. Assim, a responsabilidade legal não é percebida como um limitante, mas sim como estimulador de decisões conscientes.

Por fim, a competição é vista por Morris e Jones (1999) e por Kim (2010) como uma característica que pode levar não à disputa no setor público, mas à motivação. Seria uma forma de se espelhar em organizações públicas bemsucedidas e assim, melhorar a qualidade dos serviços públicos. No entanto, essa variável não é notada na prefeitura. Para $43 \%$ dos respondentes, a prefeitura não se espelha em outras instituições para melhorar a qualidade dos serviços oferecidos à população. A média de direcionamento da discordância foi de 2,83.

Embora esta questão tenha dividido a opinião de muitas pessoas, a maioria dos relatos afirma que transportar boas ideias de outras instituições para a prefeitura seria uma forma de melhorar a qualidade dos serviços prestados.

Assim, as três variáveis que compõem as características ambientais podem ser expressas na seguinte proposição:

QUADRO 4 - CARACTERÍSTICAS AMBIENTAIS DO EMPREENDEDORISMO
NO SETOR PÚBLICO
\begin{tabular}{|l|c|c|}
\hline $\begin{array}{l}\text { CARACTERISTICAS } \\
\text { PRESENTES }\end{array}$ & FAVORECE O EMPREENDEDORISMO PÚBLICO \\
\cline { 2 - 3 } & Na literatura & Para os entrevistados \\
\hline Influência Política & Não & Não \\
\hline $\begin{array}{l}\text { Responsabilidade } \\
\text { Legal }\end{array}$ & Não & Sim \\
\hline Competição & Sim & Sim \\
\hline
\end{tabular}

FONTE: Os autores (2016).

Deste modo, dos fatores que compõem a característica ambiental, apenas a responsabilidade legal foi percebida pelos servidores entrevistados de maneira diferente da literatura. Para eles, este é um fator que promove a tomada de decisão consciente, pois não se trata de inibir decisões, como é colocado pelos autores do

BORGES, D. A. H.; ROMANIELLO, M. M.; BRITO, M. J. Empreendedorismo no setor público: a influência das características organizacionais. Revista de Empreendedorismo e Gestão de Pequenas Empresas, v.5, n.1, 2016. 
assunto, mas sim de tomar a decisão que melhor atenderá às necessidades da população.

Diante dos resultados apresentados, verificou-se que a presença de algumas variáveis elencadas pelos estudiosos do empreendedorismo público, especialmente através dos estudos de Kim (2010), é percebida de maneira distinta pelos respondentes desta pesquisa, levando ao entendimento de que a idealização do empreendedorismo é notada distintamente dependendo da conjuntura de cada organização. Ou seja, alguns fatores vão ser entendidos como relevantes em um determinado ambiente e nada importante em outros.

Dos fatores que compõem as características estruturais, apenas a flexibilidade converge para a mesma opinião. Conquanto a presença de muitos níveis hierárquicos e de formalidade nos processos é percebida de forma contrária. Para os respondentes, são fatores que não impedem a adoção de ações, mas ao contrário, são relevantes para uma Administração Pública.

Já dos fatores relacionados às características administrativas, convergiram às opiniões a autonomia, a presença de recompensas pelo bom desempenho e a especialização técnica. Destarte, apenas a participação se mostrou como um fator que não favorece o empreendedorismo no setor público, ou dito de outra maneira, é um fator que promove a morosidade nas decisões.

Dos fatores representantes das características culturais, apenas a diversidade de objetivos divergiu a opinião entre a literatura e os entrevistados, já que para estes, ter vários objetivos específicos levariam ao objetivo maior, o que não impediria a adoção de ações empreendedoras dentro do setor público.

Por outro lado, todos concordaram que a responsabilização em prestar contas e o foco nos resultados favorece o empreendedorismo, principalmente porque está condicionado às decisões conscientes e nas demandas do cidadão.

Quanto aos fatores pertencentes às características ambientais, apenas a responsabilidade legal dividiu as opiniões dos estudiosos e dos respondentes. Enquanto para os primeiros esse fator reduz as ações empreendedoras, para os segundos estimula a tomada de decisão consciente.

BORGES, D. A. H.; ROMANIELLO, M. M.; BRITO, M. J. Empreendedorismo no setor público: a influência das características organizacionais. Revista de Empreendedorismo e Gestão de Pequenas Empresas, v.5, n.1, 2016. 
A forte influência política é vista por ambos como um fator que não favorece as ideias inovadoras, tampouco se preocupa com o bem-estar da sociedade, mas trata-se de um fator que está mais preocupado com as relações políticas.

Por fim, a competição é percebida tanto pelos literários do empreendedorismo quanto pelos servidores entrevistados como um fator que proporciona melhorias na qualidade dos serviços e que favorece a proatividade e a inovação promovendo ações empreendedoras. A competição não é percebida como a busca pelo lucro, como acontece nas organizações privadas, pelo contrário, é entendida como a busca por boas ideias, por ações bem-sucedidas e que podem ser aplicadas no setor público através de adaptações a fim de melhorar os serviços ofertados.

Logo, e diante do que foi explicitado, se fosse possível resumir uma prefeitura empreendedora pelas suas características através da perspectiva da literatura aqui apresentada e da perspectiva dos respondentes, ela seria estruturada assim:

QUADRO 5 - SÍNTESE DAS CARACTERÍSTICAS APRESENTADAS POR PREFEITURAS EMPREENDEDORAS

\begin{tabular}{|l|l|}
\hline \multicolumn{1}{|c|}{ LITERATURA } & \multicolumn{1}{|c|}{ ENTREVISTADOS } \\
\hline Presença de poucos níveis hierárquicos & $\begin{array}{l}\text { Presença de níveis hierárquicos bem } \\
\text { definidos }\end{array}$ \\
\hline Teria a formalidade mínima necessária & $\begin{array}{l}\text { Teria procedimentos formais através de } \\
\text { manuais e fluxos }\end{array}$ \\
\hline $\begin{array}{l}\text { Seria altamente flexível quanto às } \\
\text { mudanças }\end{array}$ & Seria flexível quanto às mudanças \\
\hline Daria total autonomia aos seus gestores & Daria autonomia aos seus gestores \\
\hline $\begin{array}{l}\text { Estimularia a participação de todos os } \\
\text { servidores }\end{array}$ & $\begin{array}{l}\text { Não estimularia a participação dos } \\
\text { servidores }\end{array}$ \\
\hline $\begin{array}{l}\text { Trabalharia com sistema de recompensas } \\
\text { aos servidores pelo bom desempenho }\end{array}$ & $\begin{array}{l}\text { Trabalharia com sistema de recompensas } \\
\text { aos servidores pelo bom desempenho }\end{array}$ \\
\hline Teria pessoas altamente especializadas & Teria pessoas altamente especializadas \\
\hline $\begin{array}{l}\text { Tomaria decisões conscientes com base } \\
\text { na accountability }\end{array}$ & $\begin{array}{l}\text { Tomaria decisões conscientes com base } \\
\text { na accountability }\end{array}$ \\
\hline Teria um objetivo único & $\begin{array}{l}\text { Teria objetivos específicos e não um único } \\
\text { objetivo }\end{array}$ \\
\hline Focaria nos resultados & Focaria nos resultados \\
\hline $\begin{array}{l}\text { Tomaria decisões com base técnica e não } \\
\text { política }\end{array}$ & $\begin{array}{l}\text { Tomaria decisões com base técnica e não } \\
\text { política }\end{array}$ \\
\hline $\begin{array}{l}\text { Os gestores não responderiam legalmente } \\
\text { pelos seus atos }\end{array}$ & Os gestores responderiam pelos seus atos \\
\hline A competição seria estimulada & A competição seria estimulada \\
\hline
\end{tabular}

FONTE: Os autores (2016).

De fato, ao comparar os dois modelos, percebe-se que mesmo enfatizando o empreendedorismo no setor público, as características apontadas pela literatura

BORGES, D. A. H.; ROMANIELLO, M. M.; BRITO, M. J. Empreendedorismo no setor público: a influência das características organizacionais. Revista de Empreendedorismo e Gestão de Pequenas Empresas, v.5, n.1, 2016. 
parecem ser uma transposição do setor privado e tendem a uma idealização para o setor público. Isso pode ser percebido pelo foco na ausência de responsabilidade legal e de formalidade nos procedimentos internos.

Diferente dessa visão, o modelo exposto pela perspectiva dos entrevistados parece ser mais realista, mais condizente com a realidade do setor público. Isso porque a Administração Pública possui características muito peculiares, como a realização de processos licitatórios, os quais devem estar de acordo e seguir criteriosamente o que está disposto na Lei de Licitações e Contratos AdministrativosLei $\mathrm{n}$-8666/1993, a realização dos empenhos, dos pedidos, da contratação e dos pagamentos. Tudo isso é e precisa ser regulamentado de alguma forma.

Por isso, é preciso uma análise de conjuntura para avaliar as reais condições de cada prefeitura, colocar no conjunto as práticas utilizadas pela iniciativa privada e que podem auxiliar na Administração Pública juntamente com as práticas bem-sucedidas de outras entidades públicas e é claro, as particularidades internas.

\section{Considerações Finais}

Os dados obtidos permitem concluir que as características organizacionais, de fato, influenciam a adoção de ações empreendedoras, consequentemente, a implementação do empreendedorismo no setor público. Diante disso, é preciso que os gestores públicos, especialmente os prefeitos seguidos dos secretários municipais e dos demais servidores detentores de cargos de nível estratégico, promovam e estimulem essas ideias inovadoras dentro das prefeituras junto ao corpo técnico.

No que tange às características organizacionais, foi encontrada relação positiva para os fatores hierarquia, formalidade, flexibilidade, autonomia, recompensas, especialização, accountability, multiplicidade de objetivos, a orientação para os resultados, a responsabilidade legal e a competição. Ou seja, quando presentes de forma substancial na organização pública, essas 
características influenciam positivamente, favorecendo a implementação do empreendedorismo.

Por outro lado, foi encontrada a relação negativa para os fatores participação e influência política. Dito de outra forma, quando estão presentes na organização, esses fatores não favorecem a adoção de ações empreendedoras.

Assim, este trabalho se mostra relevante para os estudos acerca do empreendedorismo no setor público, principalmente para as prefeituras municipais que podem reavaliar as suas características, adaptá-las ao ambiente interno de maneira a incentivar a adoção de ações empreendedoras junto aos servidores, criando assim, uma estrutura de prefeitura empreendedora.

É importante ressaltar que este estudo não tem a pretensão de esgotar aqui as discussões acerca deste assunto que ainda carece de muitos estudos e análises, tampouco, teve a ambição de dizer que existem modelos a serem seguidos para se implantar o empreendedorismo público. Ao contrário, o propósito foi instigar novas pesquisas e principalmente afirmar que 0 modelo quase perfeito de empreendedorismo público será aquele realizado individualmente por cada prefeitura e por cada organização pública de acordo com as suas necessidades.

Para trabalhos futuros, recomenda-se que esta pesquisa seja aplicada em outros municípios do mesmo porte a fim de tentar levantar as características que podem ser comuns entre eles. Isso posteriormente poderá ser comparado a análises de prefeituras com portes maiores de modo que se possa auxiliar os municípios e seus gestores a adotar ideias empreendedoras. Após essas novas pesquisas, será possível realizar comparações a nível nacional e também com a literatura internacional a qual conta com mais trabalhos publicados na área que o Brasil.

Quanto à metodologia e aos métodos utilizados, é possível dizer que se mostraram eficazes na busca dos resultados desejados, principalmente porque a triangulação metodológica possibilitou encontrar resposta que somente por análise quantitativa não seria possível. No entanto, a estratégia de coleta de dados pode melhorar. Recomenda-se a disponibilização de uma urna para que os questionários sejam depositados pelos respondentes a fim de que se sintam mais seguros quanto ao sigilo das informações.

BORGES, D. A. H.; ROMANIELLO, M. M.; BRITO, M. J. Empreendedorismo no setor público: a influência das características organizacionais. Revista de Empreendedorismo e Gestão de Pequenas Empresas, v.5, n.1, 2016. 


\section{Referências:}

ANDREWS, R. et al.. Centralization, organizational strategy and public service performance. Journal of Public Administration Research and Theory, p. 57-80, 2007.

BELEI, R. A. et al. O uso de entrevista, observação e videogravação em pesquisa qualitativa. Cadernos de Educação FaE/PPGE/UFPel, n. 30 p. 187-199, 2008.

BELLONE, C. J.; GOERL, G. F. Reconciling public entrepreneurship and democracy. Public Administration Review, p. 130-134, 1992.

BORINS, S. Lessons from the new public management incommonwealth nations. International Public Management Journal, p. 37-58, 1998b.

BOVENS, M. Public accountability. In: FERLIE, E.; LYNN JR., L. E.; POLLITT, C. (Eds.). The Oxford handbook of public management. Oxford, NY: Oxford University Press, 2005. p. 182-208.

BOYETT, I. The public sector entrepreneur- a definition. Journal of Public Sector Management, p. 36-51, 1996.

BOZEMAN, B. Public values and public interest: counterbalancing economic individualism. Washington, DC: Georgetown University Press, 2007.

BRASIL. Constituição: República Federativa do Brasil. Brasília, DF: Senado Federal, 1988.

BRESSER-PEREIRA, L. C. Reflexões sobre a reforma gerencial brasileira de 1995. Revista do Serviço Público, ano 50, n. 4, p. 5-30, out./dez. 1999.

CARPENTER, D. P. The forging of bureaucratic autonomy: reputation, networks and policy innovation in executive agencies, 1862-1928. Princeton, NJ: Princeton University Press, 2001.

CARTONI, D. Veris Edu. Aula 5- Tipos de Pesquisa. Metodologia Científica. 2015.

COOPER, D. R.; SCHINDLER, P. S. Métodos de pesquisa em administração. 7. ed. Porto Alegre: Bookman, 2003.

COSTA-DE-SOUZA, G. Empreendedorismo e formação profissional de administradores públicos: o caso da Empresa Júnior da Fundação João Pinheiro. In: CASI - CONGRESSO DE ADMINISTRAÇÃO, SOCIEDADE E INOVAÇÃO, 2013, Penedo. Anais... Rio de Janeiro: CASI, 2013. Disponível em: $<$ http://www.congressocasi.uff.br/?page id=77>. Acesso em 06 de junho de 2015.

CURRIE, G. et al. Entrepreneurial leadership in the english public sector: paradox or possibility? Public Administration, v. 86, n. 4, p. 987-1008. 2008.

BORGES, D. A. H.; ROMANIELLO, M. M.; BRITO, M. J. Empreendedorismo no setor público: a influência das características organizacionais. Revista de Empreendedorismo e Gestão de Pequenas Empresas, v.5, n.1, 2016. 
DALMORO, M.; VIEIRA, K. M. Dilemas na construção de escalas tipo likert: o número de itens e a disposição influenciam nos resultados? Revista Gestão Organizacional, v. 6, n. 3, p. 161-174, 2013.

DAVIDSSON, P.; LOW, M. B.; WRIGHT, M. Editor's introduction: Low and acMillan ten years on: Achievements and future directions for entrepreneurship research. Entrepreneurship Theory and Practice, v. 25, n. 4, p. 5-15, 2001.

DIEFENBACH, F. E. Entrepreneurship in the public sector: when middle managers create public value. Gabler research, Gabler Verlag Wiesbaden, 2011.

DRUCKER, P. F. Innovation and entrepreneurship: practice and principles. Londres: Butterworth-Heinemann, 1985.

EDWARDS, C. et al.. Public entrepreneurship: Rhetoric, reality, and context. International Journal of Public Administration, v. 25, n. 12, p. 1539-1554, 2002.

FREITAS, $H$. et al. O método de pesquisa survey. Revista de Administração da USP, v. 35, n. 3, p.105-112, 2000.

GIL, A. C. Métodos e Técnicas de Pesquisa Social. São Paulo: Atlas, 1999.

GODOY, A. S. Pesquisa qualitativa: tipos fundamentais. Revista de Administração de Empresas, v. 35, n. 3, p. 25-35, 1995.

HALL, R. H. Organizations: structures, processes, and outcomes. Englewood Cliffs: Prentice Hall, 1996.

HIPÓLITO BORGES, D. A.; ROMANIELLO, M. M.; BRITO, M. J. de.; Empreendedorismo no setor público: os papéis das características organizacionais. In: CONGRESSO DE INICIAÇÃO CIENTIFICA DA UFLA, 26, 2013, Lavras. Anais... Lavras: UFLA, 2013.

INGRAM, P.; CLAY, K. The choice-within-constraints new institutionalism and implications for sociology. Annual Review of Sociology, v. 26, p. 525-546, 2000.

KEARNEY, C.; HISRICH, R.; ROCHE, F. Facilitating public sector corporate entrepreneurship process: a conceptual model. Journal of Enterprising Culture, v. 15 , n. 3, p. 275-299, 2007.

KEYS, P. R. Administrative entrepreneurship in the public sector. Administration in Social Work, v. 12, n. 2, p. 59-68. 1988.

KIM, Y. Stimulating entrepreneurial practices in the public sector: The Roles of Organizational Characteristics. Administration \& Society. p. 780-814, 2010.

BORGES, D. A. H.; ROMANIELLO, M. M.; BRITO, M. J. Empreendedorismo no setor público: a influência das características organizacionais. Revista de Empreendedorismo e Gestão de Pequenas Empresas, v.5, n.1, 2016. 
LLEWELLYN, N.; JONES, G. Controversies and conceptual development: Examining public entrepreneurship. Public Management Review, v. 5, n. 2, p. 245-266, 2003.

LUMPKIN, G. T.; DESS, G. G. Linking two dimensions of entrepreneurial orientation to firm performance: The moderating role of environment and industry life cycle. Journal of Business Venturing, v. 16, n. 5, p. 429-451. 2001.

MOON, M. J. The pursuit of managerial entrepreneurship: Does organization matter? Public Administration Review, p. 31-43, 1999.

MORAIS, M. C. A.; VALADARES, J. L.; EMMENDOERFER, M.; TONELLI, D. Polissemias do empreendedorismo no setor público. Revista de Empreendedorismo e Gestão de Pequenas Empresas, v. 4, n. 1, p. 26-53, 2015.

MORRIS, M. H.; JONES, F. F. Entrepreneurship in established organizations: The case of the public sector. Entrepreneurship Theory and Practice, v. 24, n. 1, p. 71$91,1999$.

MORRIS, M. H.; KURATKO, D. F. Corporate entrepreneurship. Fort Worth: Harcourt College, 2002.

MORRIS, M. H.; KURATKO, D. F.; COVIN, J, G. Corporate entrepreneurship and innovation: Entrepreneurial development within organizatuins. Mason: Thomson/South-Western, 2008.

NUTT, P. C. Comparing public and private sector decision-making practices. Journal of Public Administration Research and Theory, v. 16, n. 2, p. 289-318, 2006.

OSBORNE, D.; GAEBLER, T. Reinventing government: how the entrepreneurial spirit is transforming the public sector. New York, 1992.

QUEIROZ, D. T. et al. Observação participante na pesquisa qualitativa: conceitos e aplicações na área da saúde. Revista de Enfermagem da UERJ, v. 15, n. 2, p. 276283, 2007.

RAINEY, H. G.; BOZEMAN, B. Comparing public and private organizations: Empirical research and the power of the a priori. Journal of Public Administration Research and Theory, v. 10, n. 2, p. 447-469, 2000.

ROBERTS, N. C. Public entrepreneurship and innovation. Policy Studies Review, v. 11, n. 1, p. 55-74, 1992.

ROBERTS, N. C.; KING, P. J. Policy entrepreneurs: Their activity structure and function in the policy process. Journal of Public Administration Research and Theory, v. 1, n. 2, p. 147-175, 1991.

STONE, J. B. Public entrepreneurship in Florida local government administration. Tallahassee: Florida State University, 1992.

BORGES, D. A. H.; ROMANIELLO, M. M.; BRITO, M. J. Empreendedorismo no setor público: a influência das características organizacionais. Revista de Empreendedorismo e Gestão de Pequenas Empresas, v.5, n.1, 2016. 
TINOCO, J. E. P. Balanço social: balanço da transparência corporativa e da concentração social. Revista Brasileira de Contabilidade, n. 135, p. 56, 2002.

VALADARES, J. L.; EMMENDOERFER, M. L. A incorporação do Empreendedorismo no Setor Público: reflexões baseadas no contexto brasileiro. Revista de Ciências da Administração, v. 17, n. 41, p. 82-98, 2015.

YIN, R. K. Estudo de caso - planejamento e métodos. 2. ed. Porto Alegre: Bookman, 2001.

\footnotetext{
' Pesquisa financiada com recursos da Fundação de Amparo à Pesquisa do Estado de Minas Gerais (FAPEMIG).
} 